\title{
Dynamic changes in lymphocyte subsets and parallel cytokine levels in patients with severe and critical COVID-19
}

Yangli Liu ${ }^{1 \dagger}$, Weiping Tan ${ }^{1 \dagger}$, Haihong Chen ${ }^{1 \dagger}$, Ying Zhu², Li Wan³ ${ }^{3}$ Ke Jiang ${ }^{3}$, Yubiao Guo ${ }^{1}$, Kejing Tang ${ }^{1}$, Canmao Xie ${ }^{1}$, Hui Yi ${ }^{1 *}$, Yukun Kuang ${ }^{1 *}$ and Yifeng Luo ${ }^{1^{*}}$

\begin{abstract}
Background: The lack of knowledge regarding the pathogenesis and host immune response during SARS-CoV-2 infection has limited the development of effective treatments. Thus, we longitudinally investigated the dynamic changes in peripheral blood lymphocyte subsets and parallel changes in cytokine levels in COVID-19 patients with different disease severities to further address disease pathogenesis.

Methods: A total of 67 patients (10 moderate, 38 severe and 19 critical cases) with COVID-19 admitted to a tertiary care hospital in Wuhan from February 8th to April 6th, 2020 were retrospectively studied. Dynamic data of lymphocyte subsets and inflammatory cytokines were collected.

Results: On admission, compared with moderate cases, severe and critical cases showed significantly decreased levels of total lymphocytes, T lymphocytes, CD4 ${ }^{+}$T cells, CD8 ${ }^{+}$T cells, B cells and NK cells. IL-6 and IL-10 were significantly higher in the critical group. During the following hospitalization period, most of the lymphocyte subsets in the critical group began to recover to levels comparable to those in the severe group from the fourth week after illness onset, except for NK cells, which recovered after the sixth week. A sustained decrease in the lymphocyte subsets and an increase in IL-6 and IL-10 were observed in the nonsurvivors until death. There was a strong negative correlation between IL- 6 and IL-10 and total lymphocytes, T lymphocytes, CD4 ${ }^{+} \mathrm{T}$ cells, CD8 ${ }^{+} \mathrm{T}$ cells and NK cells.
\end{abstract}

Conclusions: A sustained decrease in lymphocyte subsets, especially CD4 ${ }^{+} \mathrm{T}$ cells and NK cells, interacting with proinflammatory cytokine storms was associated with severe disease and poor prognosis in COVID-19.

Keywords: COVID-19, SARS-CoV-2, Dynamic changes, Lymphocyte subsets, Cytokine storm

\footnotetext{
*Correspondence: hui-yisums@163.com; stevenkyk@hotmail.com; lyif@mail.sysu.edu.cn

†Yangli Liu, Weiping Tan and Haihong Chen contributed equally to this work.

${ }^{1}$ Division of Pulmonary and Critical Care Medicine, The First Affiliated

Hospital of Sun Yat-sen University, Institute of Pulmonary Diseases, Sun

Yat-sen University, Guangzhou 510080, Province Guangdong, People's

Republic of China

Full list of author information is available at the end of the article
}

(c) The Author(s). 2021 Open Access This article is licensed under a Creative Commons Attribution 4.0 International License, which permits use, sharing, adaptation, distribution and reproduction in any medium or format, as long as you give appropriate credit to the original author(s) and the source, provide a link to the Creative Commons licence, and indicate if changes were made. The images or other third party material in this article are included in the article's Creative Commons licence, unless indicated otherwise in a credit line to the material. If material is not included in the article's Creative Commons licence and your intended use is not permitted by statutory regulation or exceeds the permitted use, you will need to obtain permission directly from the copyright holder. To view a copy of this licence, visit http://creativecommons.org/licenses/by/4.0/ The Creative Commons Public Domain Dedication waiver (http://creativecommons.org/publicdomain/zero/1.0/) applies to the data made available in this article, unless otherwise stated in a credit line to the data. 


\section{Background}

The disease caused by severe acute respiratory syndrome coronavirus 2 (SARS-CoV-2), named coronavirus disease 2019 (COVID-19), still poses a significant threat to public health worldwide. Prevention of acute respiratory distress syndrome (ARDS) and death in COVID-19 patients is an urgent health emergency. Proper treatment requires a better understanding of the pathogenesis of the disease. However, while the clinical features of COVID19 and the biological characteristics of the virus are well documented [1-4], the pathogenesis and host immune response during SARS-CoV-2 infection have been poorly studied.

A rapid reduction in peripheral blood lymphocytes, especially $\mathrm{T}$ lymphocyte subsets, was observed and confirmed to predict pneumonia development and progression to respiratory failure at the early phase of the disease (within 2 weeks after onset) caused by severe acute respiratory syndrome coronavirus in 2003 [5] and Middle East respiratory syndrome (MERS-CoV) [6]. Recent studies have also reported decreased lymphocytes, particularly $\mathrm{CD}^{+}$and $\mathrm{CD}^{+} \mathrm{T}$ cells, in the peripheral blood of COVID-19 patients were in correlation with disease severity [7-10].

Cytokine storms are also considered to be one of the major causes of ARDS or extrapulmonary multipleorgan failure, and the degree of serum cytokine levels is positively correlated with mortality rate [11, 12]. Many critically ill COVID-19 patients who suddenly deteriorated in the later stages of the disease or during recovery were found to have cytokine storms [13]. High serum levels of inflammatory mediators and severe lymphopenia suggested an unbalanced deleterious immune response in COVID-19 [1]. A study involving three COVID-19 cases found that the early immune response in COVID-19 patients was highly dynamic. Parallel changes in cytokines and lymphocyte subsets suggested that the proinflammatory response may be intertwined with $\mathrm{T}$ lymphocyte activation, possibly exacerbating the disease and prolonging infection duration [14].

However, information is lacking regarding how $\mathrm{T}$ cell responses synchronize with cytokine levels and their interactions at the acute and convalescent phases of SARS-CoV-2 infection. In this study, we longitudinally investigated the dynamic changes in peripheral blood lymphocyte subsets and parallel changes in cytokine levels in COVID-19 patients with different disease severities to further address disease pathogenesis.

\section{Methods}

\section{Study population}

This study was a single-centre retrospective study and was approved by the Ethical Committee of Human Experimentation in the Union Hospital, Tongji Medical
College, Huazhong University of Science and Technology. From February 8th to April 6th, 2020, a total of 85 hospitalized patients were laboratory diagnosed with COVID-19 after examination of SARS-CoV-2 by reverse transcription-polymerase chain reaction (RT-PCR) test from pharyngeal swab specimens in the isolation ward of the neurosurgery and thoracic surgery department of Union Hospital, Tongji Medical College, Huazhong University of Science and Technology. The diagnosis of COVID-19 was made according to the guidelines released by National Health Commission \& State Administration of Traditional Chinese Medicine (Version 7, 15]. Of them, 18 patients were excluded due to a lack of complete results for lymphocyte subset levels and inflammatory cytokines. Sixty-seven patients were included in this study and were retrospectively reviewed.

\section{Data collection}

Data from the electronic medical records system were extracted and analysed by two independent researchers. Information was collected on age, sex, days before hospitalization, hospitalization length of stay, comorbidities (including hypertension, diabetes mellitus, malignancy, chronic kidney disease and chronic lung disease), treatment and outcomes. All patients underwent routine laboratory tests, including complete blood count, liver and renal function and coagulation profile. Total lymphocytes, lymphocyte subsets ( $\mathrm{T}$ lymphocytes, $\mathrm{CD} 4^{+} \mathrm{T}$ cells, $\mathrm{CD}^{+} \mathrm{T}$ cells, B cells and NK cells) and inflammatory cytokines (IL-2, IL-4, IL-6, IL-10, TNF- $\alpha$ and IFN$\gamma)$ were first detected on the day of admission before treatment and then once a week on average during hospitalization.

\section{Lymphocyte subset analysis}

Lymphocyte subset levels were measured by BD FACS Canto flow cytometer (BD Biosciences, USA) according to the manufacturer's instructions. In brief, $50 \mu \mathrm{l}$ of whole blood was added to a BD Trucount tube and labelled with BD Multitest 6-colour (CD3/CD16+56/ CD45/CD4/CD19/CD8) TBNK reagent (BD Biosciences, USA) for $15 \mathrm{~min}$ in darkness at room temperature. Then, after adding $450 \mu \mathrm{l}$ of lysing solution, the samples were analysed with BD FACSCanto clinical software. The normal reference ranges of total lymphocytes, $\mathrm{T}$ lymphocytes $\left(\mathrm{CD}^{+}\right), \mathrm{CD}^{+} \mathrm{T}$ cells $\left(\mathrm{CD} 3^{+} \mathrm{CD} 4^{+}\right), \mathrm{CD}^{+} \mathrm{T}$ cells $\left(\mathrm{CD}^{+} \mathrm{CD}^{+}\right), \quad \mathrm{B}$ cells $\left(\mathrm{CD}^{-} \mathrm{CD} 19^{+}\right)$and NK cells $\left(\mathrm{CD}^{-} \mathrm{CD} 6^{+} \mathrm{CD} 56^{+}\right)$were $1000-3300,603-2993$, 4412156, 125-1312, 107-698 and 95-640 per $\mu \mathrm{L}$, respectively.

\section{Cytokine detection}

The concentrations of plasma cytokines (IL-2, IL-4, IL-6, IL-10, TNF- $\alpha$ and IFN- $\gamma$ ) were detected with a BD CBA 
human Th1/Th2 cytokine kit by a BD FACS Canto flow cytometer (BD Biosciences, USA) according to the manufacturer's instructions. Briefly, $3 \mathrm{ml}$ of venous blood was collected, and sera were obtained by blood centrifugation at $3500 \mathrm{r} / \mathrm{min}$ for $15 \mathrm{~min}$. Six bead populations with significant fluorescence intensity (FL4) were coated with the abovementioned cytokine-specific PE-conjugated antibodies. Next, $50 \mu \mathrm{l}$ of the cytokine capture beads were mixed with $50 \mu \mathrm{l}$ of human Th1/Th2-II PE Detection Reagent and were then incubated with recombinant standards or samples to form sandwich complexes. Subsequently, the assay tubes were incubated for $3 \mathrm{~h}$ at room temperature on a non-absorbent, dry surface. Then, $1 \mathrm{ml}$ of wash buffer was added to each assay tube and centrifuged at $200 \mathrm{~g}$ for $5 \mathrm{~min}$. After adding $300 \mu \mathrm{l}$ of wash buffer, the assay tubes were detected on a flow cytometer using FCAP Array software (Soft Flow Inc., Pecs, Hungary) to generate results in graphical and tabular format. The limits of detection for all cytokines were $1-5000 \mathrm{pg} / \mathrm{ml}$. The normal reference ranges of IL-2, IL-4, IL-6, IL-10, TNF- $\alpha$ and IFN- $\gamma$ were $0-4.1,0$ $3.2,0-2.9,0-5.0,0-23.0$ and $0-18.0(\mathrm{pg} / \mathrm{ml})$, respectively.

\section{Definitions}

The patients were divided into three groups according to the guidelines [15]: mild group, mild clinical symptoms with no abnormal radiological findings; moderate group, fever and other respiratory tract symptoms with pneumonia on chest computed tomography; severe group, meeting any of the following: (1) respiratory distress, respiratory rate $\geq 30 / \mathrm{min}$; (2) oxygen saturation on room air $\leq 93 \%$ at rest; (3) $\mathrm{PaO}_{2} / \mathrm{FIO}_{2} \leq 300 \mathrm{mmHg}$; or (4) lung infiltrates $>50 \%$ within 24 to $48 \mathrm{~h}$; and critical group, meeting any of the following: (1) respiratory failure requiring mechanical ventilation; (2) shock; or (3) other organ failure requiring monitoring and treatment in the intensive care unit (ICU).

\section{Statistical analysis}

Statistical analyses were performed with SPSS 22.0 (SPSS, Chicago, IL). Nonparametric variables are described as medians and quartile intervals (IQRs) and were compared using the Mann-Whitney U or KruskalWallis test. Categorical variables are expressed as numbers and percentages [n (\%)] and were compared using contingency table analysis and $\mathrm{X} 2$ tests. The level of IL-6 was analysed after $\log 10$ transformation. A $p$-value of less than 0.05 was considered statistically significant.

\section{Results}

\section{Baseline characteristics of COVID-19 patients}

Sixty-seven patients hospitalized with COVID-19 diseases were included, with 10 in the moderate group, 38 in the severe group, and 19 in the critical group. The median age was significantly higher in the severe and critical groups than in the moderate group $(65.0 \mathrm{y}, 66.0$ y vs. $39.5 \mathrm{y}, p=0.001)$. There was no significant difference in sex, days from illness onset to admission, or comorbidity distribution between the three groups. Hospitalization length of stay was much longer in the severe and critical group than in the moderate group (37.0 (IQR, 19.8-46.3), 44.0 (IQR, 27.0-50.0) vs. 16.5 (IQR, 10.0-20.3), $p=0.003)$. Most patients received empirical broad-spectrum antibiotics (moxifloxacin and/or cephalosporin) with a combination of antiviral treatment (arbidol) at the early phase (within 2 weeks after onset) of the disease. Sixteen $(84.2 \%)$ of the critical patients, 20 (52.6\%) of the severe patients and $1(10.0 \%)$ of the moderate patients received empirical treatment with prednisolone $0.5 \mathrm{mg} / \mathrm{kg} /$ day for no longer than 7 days after admission. Four patients $(21.1 \%)$ in the critical group died in the hospital (Table 1).

\section{Lymphocyte subset levels and inflammatory status on admission}

Absolute counts of lymphocyte subsets were compared in the three groups on admission before treatment (Table 1). The median absolute total lymphocytes, $\mathrm{T}$ lymphocytes and $\mathrm{CD}_{4}{ }^{+} \mathrm{T}$-cells were significantly lower in severe cases $(1280,821,522$, per $\mu \mathrm{L}$, respectively) than in moderate cases $(2005,1413$ and 940 per $\mu \mathrm{L}$, respectively). They were reduced more profoundly in critical cases $\left(800,639\right.$ and 377 , per $\mu \mathrm{L}$, respectively). $\mathrm{CD}^{+} \mathrm{T}$ cells and B cells were significantly decreased in critical cases compared with moderate cases $(213$ and 97 per $\mu \mathrm{L}$ vs. 443 and 221 per $\mu \mathrm{L}$, respectively, $P<0.01$ ), while no significant difference was found between the severe and critical groups. NK cells were significantly reduced in the critical group compared to both the moderate and severe groups ( 39 vs. $137,118, P=0.001$ ). No significant difference was observed in the percentages of $\mathrm{T}$ lymphocytes, $\mathrm{CD} 4^{+} \mathrm{T}$-cells, $\mathrm{CD} 8^{+} \mathrm{T}$-cells, $\mathrm{CD} 4^{+} / \mathrm{CD} 8^{+}$ratio, $\mathrm{B}$ cells or NK cells between the three groups $(P>0.05$, data not shown).

Plasma cytokine levels on admission were further examined (Table 1). C-reactive protein (CRP) was significantly elevated in critical cases compared to moderate and severe cases $(p=0.004)$. The levels of interleukin 6 (IL-6) and IL-10 were markedly higher in critical cases than in moderate cases $(14.5$ and $5.4 \mathrm{pg} / \mathrm{ml}$ vs. 5.8 and $4.0 \mathrm{pg} / \mathrm{ml}, p<0.05)$. No difference was found between the three groups in the levels of IL-2, IL-4, tumour necrosis factor $\alpha$ (TNF- $\alpha$ ) and interferon $\gamma$ (IFN- $\gamma$ ) on admission.

\section{Dynamic changes in lymphocyte subsets in severe and critical COVID-19}

The moderate group was not included in this part because dynamic data were not available. Since the median 
Table 1 Comparison of baseline characteristics, immunological and cytokine parameters between patients with COVID-19

\begin{tabular}{|c|c|c|c|c|}
\hline Variables & $\begin{array}{l}\text { Moderate } \\
(n=10)\end{array}$ & $\begin{array}{l}\text { Severe } \\
(n=38)\end{array}$ & $\begin{array}{l}\text { Critical } \\
(n=19)\end{array}$ & $P$ value \\
\hline Age, y & $39.5(36.0-62.5)$ & $65.0(57.0-72.3)^{*}$ & $66(56.0-70.0)^{*}$ & 0.001 \\
\hline Male & 6 & 19 & 14 & 0.230 \\
\hline Days from illness onset to admission, $d$ & $22.5(14.0-32.0)$ & $14.0(10.0-23.0)$ & $14.0(10.0-20.0)$ & 0.153 \\
\hline Length of stay, $d$ & $16.5(10.0-20.3)$ & $37.0(19.8-46.3) *$ & $44.0(27.0-50.0) *$ & 0.003 \\
\hline \multicolumn{5}{|l|}{ Comorbidities } \\
\hline Hypertension & $4(40.0)$ & $16(42.1)$ & $12(63.2)$ & 0.282 \\
\hline Diabetes mellitus & $1(10.0)$ & $12(31.5)$ & $3(15.8)$ & 0.225 \\
\hline Malignancy & $1(10.0)$ & $2(5.3)$ & $0(0.0)$ & 0.436 \\
\hline Chronic kidney disease & $0(0.0)$ & $2(5.3)$ & $1(5.3)$ & 0.759 \\
\hline Chronic lung disease & $0(0.0)$ & $5(13.2)$ & $5(26.3)$ & 0.150 \\
\hline \multicolumn{5}{|l|}{ Treatment } \\
\hline Antibiotics & $9(90.0)$ & $28(73.7)$ & $18(94.7)$ & 0.115 \\
\hline Antiviral treatment & $7(70.0)$ & $34(89.5)$ & $18(94.7)$ & 0.137 \\
\hline Corticosteroid & $1(10.0)$ & $20(52.6)$ & $16(84.2)$ & 0.001 \\
\hline Death & $0(0.0)$ & $0(0.0)$ & $4(21.1)$ & 0.01 \\
\hline \multicolumn{5}{|l|}{ Cell counts, per $\mu \mathrm{L}$} \\
\hline Total lymphocytes & 2005 (1635-2458) & $1280(950-1550) *$ & 800 (510-1050) \# * & $<0.001$ \\
\hline T lymphocytes & $1413(1236-2010)$ & $821(609-1142) *$ & 639 (443-725) \# * & 0.002 \\
\hline $\mathrm{CD}^{+} \mathrm{T}$-cell & $940(664-1292)$ & $522(358-735) *$ & $377(302-467) \#^{*}$ & 0.001 \\
\hline $\mathrm{CD}^{+}{ }^{\mathrm{T}}$-cell & $443(317-647)$ & $243(183-394) *$ & $213(78-264) *$ & 0.002 \\
\hline B cell & $221(135-377)$ & $137(84-210) *$ & $97(45-128) *$ & 0.001 \\
\hline NK-cell & 137 (96-208) & $118(77-189)$ & $39(19-65) \#^{*}$ & 0.001 \\
\hline \multicolumn{5}{|l|}{ Inflammatory cytokine } \\
\hline C-reactive protein, mg/L & $3.9(0.1-15.5)$ & $10.5(4.2-25.7)$ & $40.0(15.9-58.7) \#{ }^{*}$ & 0.004 \\
\hline IL-2 (pg/ml) & $3.6(3.0-4.2)$ & $2.9(2.1-4.0)$ & $3.0(2.1-3.8)$ & 0.339 \\
\hline IL-4 (pg/ml) & $2.9(1.9-3.9)$ & $3.0(1.3-3.8)$ & $2.5(1.4-3.9)$ & 0.844 \\
\hline IL-6 (pg/ml) & $5.8(3.4-8.0)$ & $6.8(4.3-16.2)$ & $14.5(5.7-52.3) *$ & 0.043 \\
\hline IL-10 (pg/ml) & $4.0(3.1-5.1)$ & $4.5(3.0-5.9)$ & $5.4(3.4-7.5) *$ & 0.049 \\
\hline TNF-a (pg/ml) & $2.7(1.7-3.4)$ & $2.1(1.6-3.2)$ & $2.6(1.7-3.2)$ & 0.325 \\
\hline IFN- $\gamma(\mathrm{pg} / \mathrm{ml})$ & $2.6(2.3-3.7)$ & $3.1(1.4-4.1)$ & $2.8(1.5-3.8)$ & 0.527 \\
\hline
\end{tabular}

Values are median (IQR) or $\mathrm{n}(\%) .{ }^{*}$ and \# refer to $P<0.05 .{ }^{*}$ Comparison between the moderate group and the severe or critical group. \# Comparison between the severe group and the critical group

IL Interleukin; TNF- $a$ Tumor necrosis factor $a$; IFN- $\boldsymbol{\gamma}$ Interferon $\boldsymbol{\gamma}$

time from illness onset to admission was 14 days in the severe and critical groups, the lymphocyte subset data in the first 2 weeks were too limited to analyse. We observed the dynamic changes in SARS-CoV-2 infection for the severe and critical groups starting from week 3. Additionally, data from four nonsurvivors are presented (Fig. 1).

Significant decrease in total lymphocytes, $\mathrm{T}$ lymphocytes and $\mathrm{CD}^{+} \mathrm{T}$ cells were observed in the critical group in the first 3 weeks. Then, they gradually increased and reached levels comparable to those in the severe group from the fourth week after illness onset, after which the median returned to the lower limit of normal (LLN) value (Fig. 1a, b, d). The decrease in $\mathrm{CD}^{+} \mathrm{T}$ cells lasted longer in the critical group for over 4 weeks and did not return to LLN until week 6 (Fig. 1c). However, a sustained decrease in the total lymphocyte, $\mathrm{T}$ lymphocyte, $\mathrm{CD} 4^{+}$, and $\mathrm{CD} 8^{+} \mathrm{T}$ cell groups was observed in the nonsurvivors until death. A significant reduction in NK cells lasted even longer until week 5 for the critical group, and they began to exceed LLN from week 6. A similar trend was observed in the nonsurvivors (Fig. 1f). B cells fluctuated near the LLN, and no significant differences were found between the two groups over the whole course of the disease (Fig. 1e). 


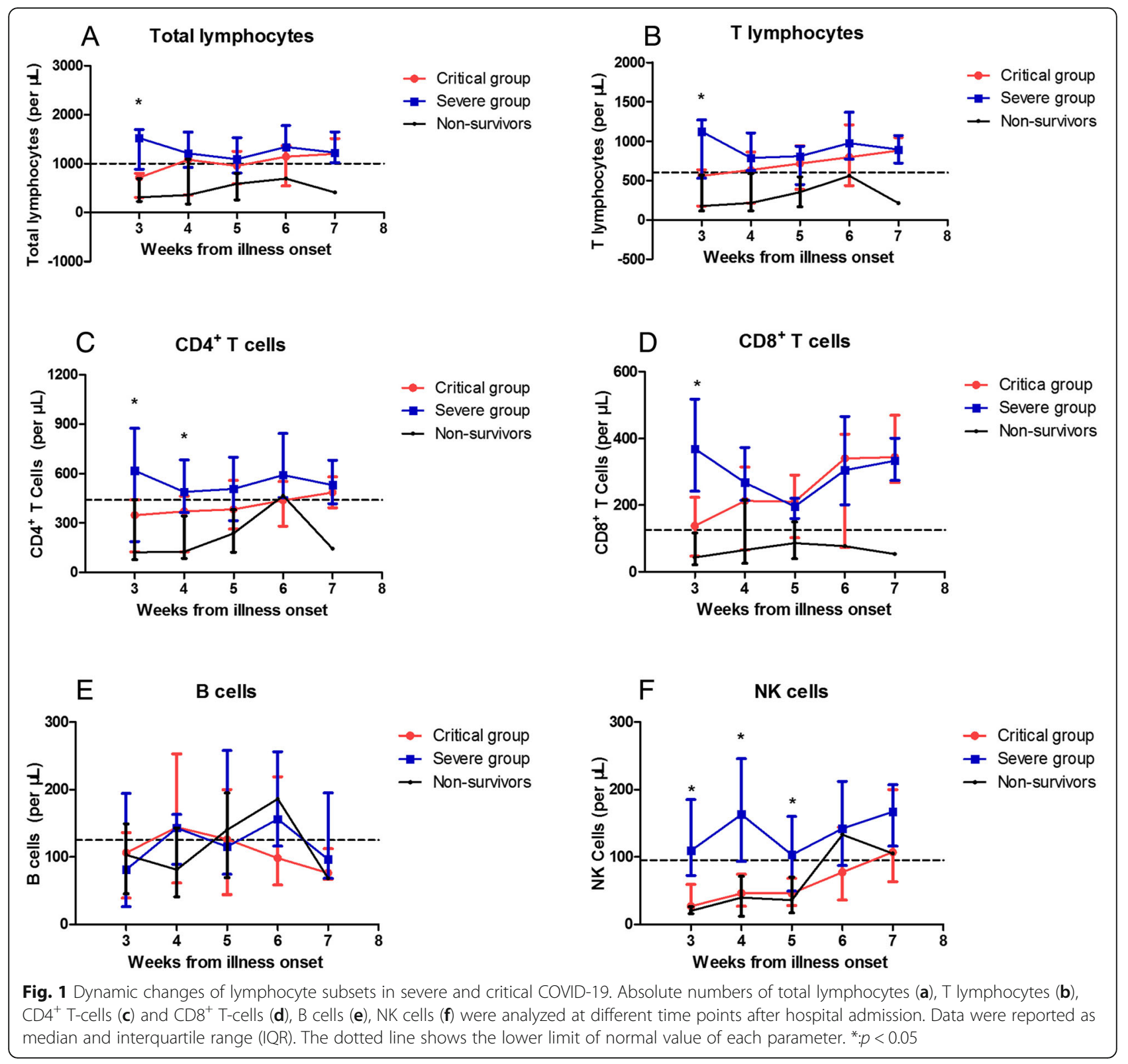

Dynamic changes in inflammatory cytokines in severe and critical COVID-19

We further analysed the parallel changes in serum inflammatory cytokine levels, including IL-2, IL-4, IL-6, IL-10, IFN- $\gamma$ and TNF- $\alpha$ (Fig. 2). No significant difference was observed between the critical and severe groups in the dynamic changes in IL-2, IL-4, TNF- $\alpha$ and IFN- $\gamma$. IL-2 and IL- 4 were in the normal range in the first 5 weeks and started to fluctuate around the normal upper limit from week six (Fig. 2a, b). Fluctuations of TNF- $\alpha$ and IFN- $\gamma$ in all the patients were minimal, and they were at very low levels from week 3 to week 7 (Fig. 2e, f). Elevation of IL-6 lasted for the whole observation course. In the severe group, it began to decline from week 6; in the critical group, it was sustained at a high level, especially in the nonsurvivors (Fig. 2c). A similar trend was seen in IL-10, and the nonsurvivors presented a significantly elevated level until death (Fig. 2d).

\section{Correlation of lymphocyte subsets and inflammatory cytokines}

To define possible associations among lymphocyte subsets and inflammatory cytokines, we assessed correlations between them. A strong negative correlation was observed between IL- 6 and total lymphocytes, T lymphocytes, $\mathrm{CD} 4^{+} \mathrm{T}$ cells and $\mathrm{CD} 8^{+} \mathrm{T}$ cells. IL- 6 was negatively correlated with NK cells as well, indicating that an inflammatory environment may suppress both innate 


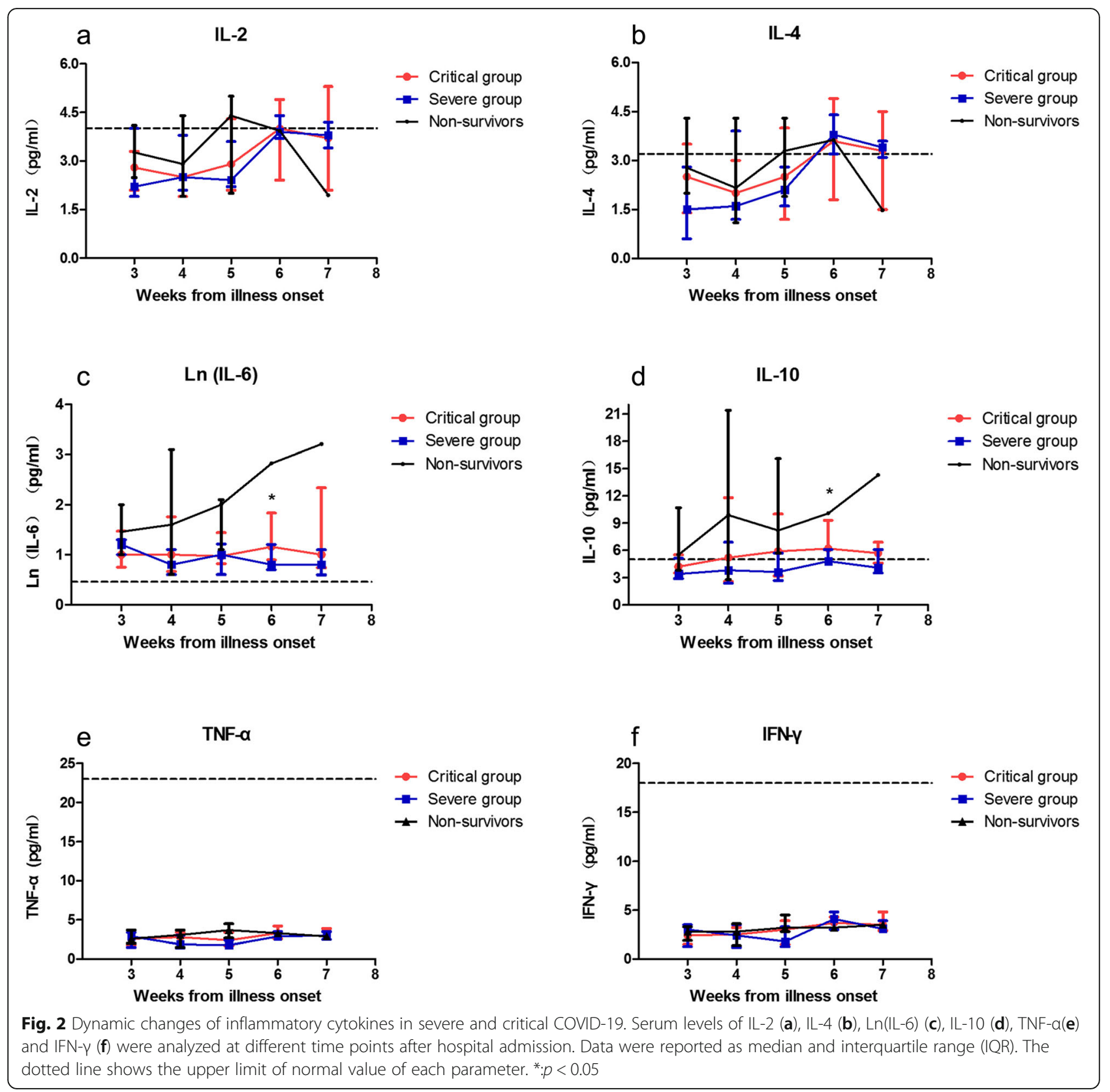

(NK) and adaptive (CD3) immune cells (Fig. 3). Similar adverse effects were also observed between IL-10 and total lymphocytes, $\mathrm{T}$ lymphocytes, $\mathrm{CD} 4^{+} \mathrm{T}$ cells and $\mathrm{CD}^{+} \mathrm{T}$ cells (Fig. 4).

\section{Discussion}

In this study, we longitudinally investigated the dynamics of peripheral immune cells and inflammatory cytokines in 67 COVID-19 patients with different disease severities and found that critical cases showed significantly decreased lymphocyte subsets and increased IL-6 and IL-10 levels on admission. Most of the parameters began to recover to comparable levels to those in the severe group from the fourth week after illness onset, except for NK cells, which recovered later from the sixth week. A sustained decrease in lymphocyte subsets and an increase in IL- 6 and IL-10 were observed in the nonsurvivors until death. There was a strong negative correlation between IL- 6 , IL-10 and total lymphocytes, T lymphocytes, $\mathrm{CD} 4^{+} \mathrm{T}$ cells, $\mathrm{CD} 8^{+} \mathrm{T}$ cells and NK cells.

Lymphopenia was observed in most of the critical cases with COVID-19 on admission and could be a potential predictor for prognosis, as reported in recently published studies $[8,16-18]$. Further analysis of the lymphocyte subsets also showed a significant decline in $\mathrm{T}$ lymphocytes, $\mathrm{CD} 4^{+} \mathrm{T}$ cells, $\mathrm{CD} 8^{+} \mathrm{T}$ cells, $\mathrm{B}$ cells, and 

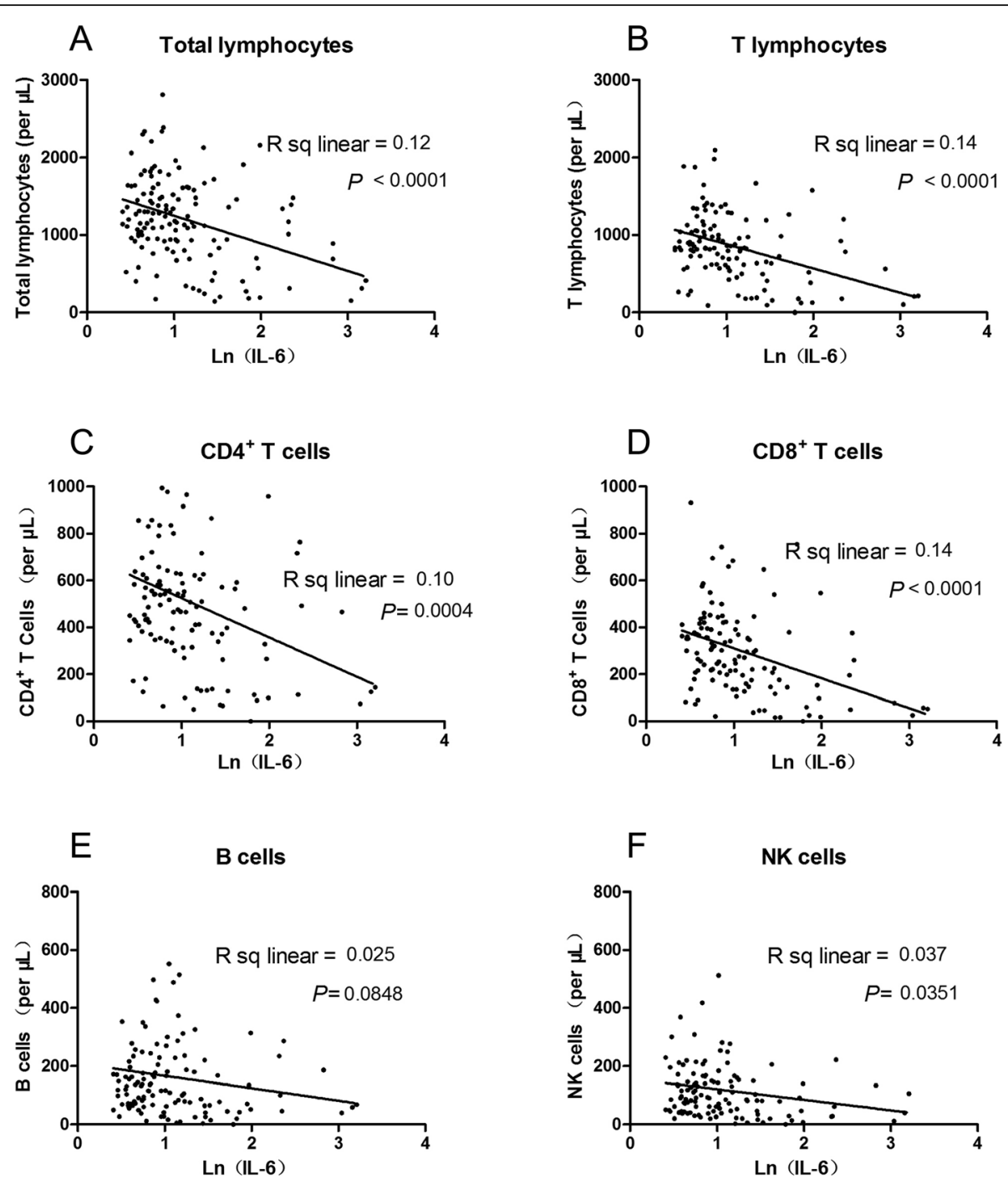

Fig. 3 Correlation analysis between IL-6 and lymphocyte subsets. Correlation between Ln (IL-6) and total lymphocytes (a), T lymphocytes (b), $\mathrm{CD}^{+}$T-cells (c) and CD8 ${ }^{+}$T-cells (d), B cells (e), NK cells (f) were shown

NK cells associated with disease severity, indicating possible dysfunction of the immune response during SARSCoV-2 infection. The mechanism of the reduction in lymphocytes might include immune injuries caused by deregulated cytokine production [1], up-regulation of apoptosis and autophagy in lymphocytes [19], lung tissue recruitment of immune cells [20] and destruction of lymphatic organs, including the spleen and lymph nodes [21]. Whether SARS-COV-2 can directly infect lymphocytes requires more detailed studies.

A recent meta-analysis demonstrated that alterations of lymphocyte subsets after treatment, rather than baseline levels, were reliable indicators for predicting COVID-19 progression or mortality [22]. In this study, by observing the dynamic changes in lymphocyte subsets during the course of COVID-19, we further confirmed the correlation between lymphocyte subset alterations and the severity of the disease. The lymphocyte subsets in the critical cases were always lower than those in the severe group. After treatment, they gradually increased to levels comparable to those in the severe group at the fourth week and then recovered to the normal level before discharge. However, the decrease was sustained in nonsurvivors, suggesting that the recovery of lymphocytes was associated with prognosis. Moreover, we observed a more significant and longer-lasting reduction in $\mathrm{CD}^{+}{ }^{+} \mathrm{T}$ cells than in $\mathrm{CD}^{+} \mathrm{T}$ cells, suggesting that $\mathrm{CD}^{+}{ }^{+} \mathrm{T}$ cells may be the primary participants in controlling SARS-CoV-2. This is in line with recent studies reporting that SARS-CoV-2-specific $\mathrm{CD}^{+} \mathrm{T}$ cell responses predominate over $\mathrm{CD}^{+} \mathrm{T}$ cell responses and that $\mathrm{CD} 4^{+} \mathrm{T}$ cell cytopenias are a characteristic change in severe COVID-19 [23, 24]. However, it is not yet conclusive which lymphocyte subsets are preferentially 

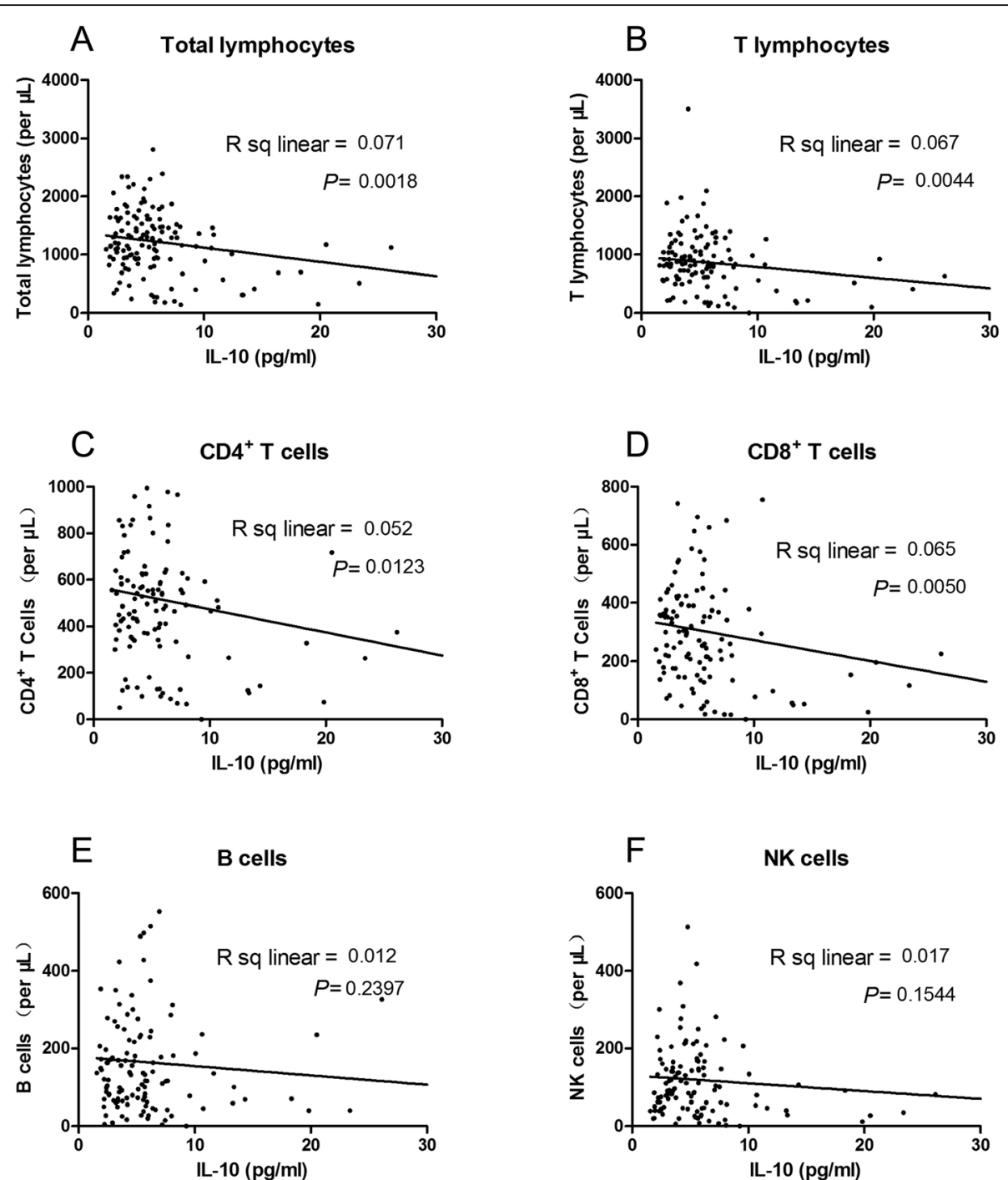

Fig. 4 Correlation analysis between IL-10 and lymphocyte subsets. Correlation between IL-10 and total lymphocytes (a), T lymphocytes (b), CD4 ${ }^{+}$ T-cells (c) and CD8 ${ }^{+}$T-cells (d), B cells (e), NK cells (f) were shown

involved in either protective or pathogenic immunity. CD4 ${ }^{+}$ and $\mathrm{CD}^{+} \mathrm{T}$ cell responses were both reported in the acute and early convalescent phases of SARS-COV-2 infection, dominated by a Th1 response [25]. A more profound understanding of $\mathrm{T}$ cell immunity would be beneficial for the design of vaccines and new treatment strategies. In addition, our observation of the dynamic changes of NK cells showed that NK cells were the last to return to normal, which might be partially explained by COVID-19 directly infecting NK cells and inhibiting their functions [26] due to the expression of angiotensin-converting enzyme 2 (ACE2) on NK cells [27]. The delayed recovery of NK cells may support the hypothesis that innate immunity plays a greater role in determining disease progression; therefore, intervention to promote the innate immune system should be further considered [28].
Cytokine release syndrome (CRS) is common in patients with severe COVID-19 and correlates with respiratory failure, ARDS, and adverse clinical outcomes [29]. Previous studies have reported that significantly higher inflammatory cytokines were associated with the disease severity of COVID-19 [30]. Our study also demonstrated that IL-6, IL-10 and CRP, a protein driven by IL-6, were all positively correlated with the severity of the disease. Moreover, while lymphocytes returned to the normal range 1 month after illness onset, the elevation of IL-6 and IL-10 in the critical group lasted for the whole observation course until clinical improvement and discharge. A sustained hyperinflammatory response in patients after discharge was also reported by Wen et al. [31]. Recently, a study from Italy reported that $10.9 \%$ $(125 / 1146)$ of discharged patients had a persistent 
infection or recurrence of COVID-19; among them 23.2\% developed new clinical symptoms [32]. Accordingly, the need for longitudinal observation of recovered patients was suggested to better understand the disease patterns. Additionally, we found that IL-2 and IL-4 were elevated and exceeded the normal upper limit at the same time point of recovery of lymphopenia before discharge, indicating that they might be beneficial to the recovery process. IFN- $\gamma$ and TNF- $\alpha$ were well below the reference range during the whole observation period as previously described [33], suggesting an immunosuppressive state with a decreased capacity to clear the virus.

IL-6 and IL-10 may impact the protective immune response by reducing the number of NK and T cells, thereby reducing the cytotoxic activity against infected cells [34], supported by our analysis that IL- 6 and IL- 10 were negatively correlated with T lymphocyte subsets and NK cells. Indeed, IL-6 has been confirmed to block lymphopoiesis [35] and inhibit natural killer cell cytotoxicity in humans [36]. IL-10 was also shown to play a suppressive role in T cell proliferation [37]. Based on the evidence that hyperinflammatory responses can lead to a cytokine storm and subsequent exhaustion of immune cells, therapeutic approaches targeting cytokines have attracted substantial investment. Among them, the IL-6 antagonist tocilizumab has been the most widely explored. However, the findings of published randomized controlled trials (RCTs) [38-40] seem controversial. While Stone et al.'s study [38] showed no mortality benefit in moderately ill patients with COVID19 , Hermine et al. found that tocilizumab may reduce the 14-day but not 28-day mortality [39]. More evidence is needed to determine the patient populations who might benefit most from treatments with tocilizumab, and a deeper understanding of the immune responses of SARSCOV-2 infection would help provide this important insight.

This study had several limitations. First, the retrospective design has inherent limitations of information biases and possible confounding data. Second, since the median time from illness onset to admission was 14 days in our study, lymphocyte subset and cytokine data in the first 2 weeks were too limited to analyse. Third, although no effective treatment was proven, the effects of antiviral drugs and corticosteroids need to be further explored. Thus, well-designed prospective studies should be performed to better understand the pathogenesis of COVID-19.

\section{Conclusions}

In conclusion, a sustained decrease in lymphocyte subsets, especially $\mathrm{CD}^{+}{ }^{+} \mathrm{T}$ cells and NK cells, interacting with proinflammatory cytokine storms was associated with severe disease and poor prognosis in COVID-19. These findings might be helpful in elucidating the disease pathogenesis of COVID-19 and in developing new therapeutic strategies.

\section{Abbreviations}

COVID-19: Coronavirus disease 2019; SARS-CoV-2: Severe acute respiratory syndrome coronavirus; ARDS: Acute respiratory distress syndrome; MERS: Middle East respiratory syndrome; RT-PCR: Real-time reversetranscriptase polymerase chain reaction; L: Interleukin; TNF-a: Tumor necrosis

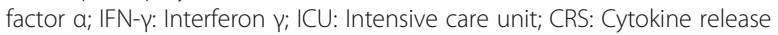
syndrome; CRP: C-reactive protein; LLN: Lower limit of normal; ULN: Upper limit of normal

\section{Acknowledgements \\ Not Applicable.}

\section{Authors' contributions}

WPT, YKK, LW and KJ collected the data, YLL, HHC and YZ participated in data analysis and contributed to manuscript writing. YBG, KJT and CMX analyzed the results. YLL, HY and YFL designed the study and critically reviewed the manuscript. All authors revised the manuscript and approved the final form.

Funding

The author(s) received no specific funding for this work.

\section{Availability of data and materials}

The datasets used during the current study are available from the corresponding author on reasonable request.

Ethics approval and consent to participate

The study protocol was approved by the Ethical Committee of Human Experimentation in the Union Hospital, Tongji Medical College, Huazhong University of Science and Technology (ID: 20200177). The approval included permission to access the inpatient medical records and the waiver of informed consent of the patients since all the data were collected retrospectively and were anonymised before use.

\section{Consent for publication}

Not applicable.

\section{Competing interests}

All the authors declare no competing interests.

\section{Author details}

${ }^{1}$ Division of Pulmonary and Critical Care Medicine, The First Affiliated Hospital of Sun Yat-sen University, Institute of Pulmonary Diseases, Sun Yat-sen University, Guangzhou 510080, Province Guangdong, People's Republic of China. ${ }^{2}$ Department of Radiology, The First Affiliated Hospital of Sun Yat-sen University, Guangzhou 510080, Province Guangdong, People's Republic of China. ${ }^{3}$ Thoracic surgery department, Union Hospital, Tongji Medical College, Huazhong University of Science and Technology, Wuhan 430000, Province Hubei, People's Republic of China.

Received: 2 June 2020 Accepted: 12 January 2021

Published online: 18 January 2021

\section{References}

1. Huang C, Wang Y, Li X, Ren L, Zhao J, Hu Y, et al. Clinical features of patients infected with 2019 novel coronavirus in Wuhan, China. Lancet. 2020;395(10223):497-506.

2. Wang D, Hu B, Hu C, Zhu F, Liu X, Zhang J, et al. Clinical characteristics of 138 hospitalized patients with 2019 novel coronavirus-infected pneumonia in Wuhan, China. JAMA. 2020;323(11):1061-9.

3. Wu Z, McGoogan JM. Characteristics of and important lessons from the coronavirus disease 2019 (COVID-19) outbreak in China: summary of a report of 72314 cases from the Chinese Center for Disease Control and Prevention. JAMA. 2020;323(13):1239-42.

4. $\mathrm{Xu} X W, W u X X$, Jiang $X G, X u K J$, Ying $L J, M a C L$, et al. Clinical findings in a group of patients infected with the 2019 novel coronavirus (SARS-Cov-2) outside of Wuhan, China: retrospective case series. BMJ. 2020;368:m606.

5. Li T, Qiu Z, Zhang L, Han Y, He W, Liu Z, et al. Significant changes of peripheral T lymphocyte subsets in patients with severe acute respiratory syndrome. J Infect Dis. 2004;189(4):648-51. 
6. Ko JH, Park GE, Lee JY, Lee JY, Cho SY, Ha YE, et al. Predictive factors for pneumonia development and progression to respiratory failure in MERSCoV infected patients. J Inf Secur. 2016;73(5):468-75.

7. Chen G, Wu D, Guo W, Cao Y, Huang D, Wang H, et al. Clinical and immunological features of severe and moderate coronavirus disease 2019. J Clin Invest. 2020;130(5):2620-9.

8. Liu J, Li S, Liu J, Liang B, Wang X, Wang H, et al. Longitudinal characteristics of lymphocyte responses and cytokine profiles in the peripheral blood of SARS-CoV-2 infected patients. EBioMedicine. 2020;55:102763.

9. Liu Z, Long W, Tu M, Chen S, Huang Y, Wang S, et al. Lymphocyte subset (CD4+, CD8+) counts reflect the severity of infection and predict the clinical outcomes in patients with COVID-19. J Inf Secur. 2020;81(2):318-56.

10. Wang F, Nie J, Wang H, Zhao Q, Xiong Y, Deng L, et al. Characteristics of peripheral lymphocyte subset alteration in COVID-19 pneumonia. J Infect Dis. 2020;221(11):1762-9.

11. Chousterman BG, Swirski FK, Weber GF. Cytokine storm and sepsis disease pathogenesis. Semin Immunopathol. 2017;39(5):517-28,

12. Ye Q, Wang B, Mao J. The pathogenesis and treatment of the 'cytokine Storm' in COVID-19. J Inf Secur. 2020;80(6):607-13.

13. Special Expert Group for Control of the Epidemic of Novel Coronavirus Pneumonia of the Chinese Preventive Medicine Association. An update on the epidemiological characteristics of novel coronavirus pneumonia (COVID19). Zhonghua Liu Xing Bing Xue Za Zhi. 2020:41(2):139-44.

14. Ong EZ, YFZ C, Leong WY, NMY L, Kalimuddin S, Haja MSM, et al. A dynamic immune response shapes COVID-19 progression. Cell Host Microbe. 2020;27(6):879-82.e2.

15. National Health Commission \& National Administration of Traditional Chinese Medicine. Diagnosis and Treatment Protocol for Novel Coronavirus Pneumonia (Trial Version 7). Chin Med J (Engl). 2020;133(9):1087-95.

16. Chen R, Sang L, Jiang M, Yang Z, Jia N, Fu W, et al. Longitudinal hematologic and immunologic variations associated with the progression of COVID-19 patients in China. J Allergy Clin Immunol. 2020;146(1):89-100.

17. Deng Z, Zhang M, Zhu T, Zhili N, Liu Z, Xiang R, et al. Dynamic changes in peripheral blood lymphocyte subsets in adult patients with COVID-19. Int Infect Dis. 2020;98:353-8.

18. Zeng HL, Lu QB, Yang Q, Wang X, Yue DY, Zhang LK, et al. Longitudinal profile of laboratory parameters and their application in the prediction for fatal outcome among patients infected with SARS-CoV-2: a retrospective cohort study. Clin Infect Dis. 2020.

19. Xiong Y, Liu Y, Cao L, Wang D, Guo M, Jiang A, et al. Transcriptomic characteristics of bronchoalveolar lavage fluid and peripheral blood mononuclear cells in COVID-19 patients. Emerg Microbes Infect. 2020;9(1): $761-70$

20. Xu Z, Shi L, Wang Y, Zhang J, Huang L, Zhang C, et al. Pathological findings of COVID-19 associated with acute respiratory distress syndrome. Lancet Respir Med. 2020;8(4):420-2.

21. Lax SF, Skok K, Zechner P, Kessler HH, Kaufmann N, Koelblinger C, et al. Pulmonary arterial thrombosis in COVID-19 with fatal outcome : results from a prospective, single-center, clinicopathologic case series. Ann Intern Med. 2020;173(5):350-61.

22. Lu Q, Wang Z, Yin Y, Zhao Y, Tao P, Zhong P. Association of peripheral lymphocyte and the subset levels with the progression and mortality of COVID-19: a systematic review and meta-analysis. Front Med (Lausanne). 2020;7:558545

23. Law JC, Koh WH, Budylowski P, Lin J, Yue F, Abe KT, et al. Systematic Examination of Antigen-Specific Recall T Cell Responses to SARSCoV-2 versus Influenza Virus Reveals a Distinct Inflammatory Profile. J Immunol. 2021;206(1):37-50.

24. Giamarellos-Bourboulis EJ, Netea MG, Rovina N, Akinosoglou K, Antoniadou A, Antonakos N, et al. Complex immune dysregulation in covid-19 patients with severe respiratory failure. Cell Host Microbe. 2020;27(6):992-1000.e3.

25. Altmann DM, Boyton RJ. SARS-CoV-2 T cell immunity: Specificity, function, durability, and role in protection. Sci Immunol. 2020;5(49):eabd6160.

26. Bortolotti D, Gentili V, Rizzo S, Rotola A, Rizzo R. SARS-CoV-2 Spike 1 Protein Controls Natural Killer Cell Activation via the HLAE/NKG2A Pathway. Cells. 2020;9(9):1975.

27. Osman MS, van Eeden C, Cohen TJW. Fatal COVID-19 infections: is NK cell dysfunction a link with autoimmune HLH. Autoimmun Rev. 2020;19(7): 102561

28. Akbari $\mathrm{H}$, Tabrizi R, Lankarani KB, Aria $\mathrm{H}$, Vakili $\mathrm{S}$, Asadian F, et al. The role of cytokine profile and lymphocyte subsets in the severity of coronavirus disease 2019 (COVID-19): a systematic review and meta-analysis. Life Sci. 2020;258:118167.

29. Ruan Q, Yang K, Wang W, et al. Clinical predictors of mortality due to COVID-19 based on an analysis of data of 150 patients from Wuhan, China. Intensive Care Med. 2020;46(5):846-8.

30. Moore JB, June CH. Cytokine release syndrome in severe COVID-19. Science. 2020;368(6490):473-4.

31. Wen W, Su W, Tang H, Le W, Zhang X, Zheng Y, et al. Immune cell profiling of COVID-19 patients in the recovery stage by single-cell sequencing. Cell Discov. 2020;6:31.

32. Bongiovanni $\mathrm{M}$, Vignati $\mathrm{M}$, Giuliani $\mathrm{G}$, Manes $\mathrm{G}$, Arienti S, Pelucchi L, et al. The dilemma of COVID-19 recurrence after clinical recovery. J Infect. 2020; 81(6):979-97.

33. Luo W, Zhang JW, Zhang W, Lin YL, Wang Q. Circulating levels of IL-2, IL-4, TNF-a, IFN- - , and C-reactive protein are not associated with severityof COVID-19 symptoms. J Med Virol. 2020. https://doi.org/10.1002/jmv.26156.

34. Bordoni V, Sacchi A, Cimini E, Notari S, Grassi G, Tartaglia E, et al. An Inflammatory Profile Correlates With Decreased Frequency of Cytotoxic Cellsin Coronavirus Disease 2019. Clin Infect Dis. 2020;71(16):2272-5.

35. Maeda K, Baba Y, Nagai Y, Miyazaki K, Malykhin A, Nakamura K, et al. IL-6 blocks a discrete early step in lymphopoiesis. Blood. 2005;106(3):879-85.

36. Wu W, Dietze KK, Gibbert K, Lang KS, Trilling M, Yan H, et al. TLR ligand induced IL-6 counter-regulates the anti-viral CD8(+) T cell response during an acute retrovirus infection. Sci Rep. 2015;5:10501.

37. Sturm R, Xanthopoulos L, Heftrig D, Oppermann E, Vrdoljak T, Dunay IR, et al. Regulatory T Cells Modulate CD4 Proliferation after Severe Traumavia IL-10. J Clin Med. 2020;9(4):1052.

38. Stone JH, Frigault MJ, Serling-Boyd NJ, Fernandes AD, Harvey L, Foulkes AS, et al. Efficacy of Tocilizumab in Patients Hospitalized with Covid-19. NEngl J Med. 2020;383(24):2333-44.

39. Hermine O, Mariette X, Tharaux PL, Resche-Rigon M, Porcher R, Ravaud P, et al. Effect of Tocilizumab vs Usual Care in Adults Hospitalized With COVID19 and Moderate or Severe Pneumonia: A Randomized Clinical Trial. JAMA Intern Med. 2021;181(1):32-40.

40. Salvarani C, Dolci G, Massari M, Merlo DF, Cavuto S, Savoldi L, et al. Effect of Tocilizumab vs Standard Care on Clinical Worsening in PatientsHospitalized With COVID-19 Pneumonia: A Randomized Clinical Trial. JAMA Intern Med. 2021;181(1):24-31.

\section{Publisher's Note}

Springer Nature remains neutral with regard to jurisdictional claims in published maps and institutional affiliations.
Ready to submit your research? Choose BMC and benefit from:
- fast, convenient online submission
- thorough peer review by experienced researchers in your field
- rapid publication on acceptance
- support for research data, including large and complex data types
- gold Open Access which fosters wider collaboration and increased citations
- maximum visibility for your research: over $100 \mathrm{M}$ website views per year
At BMC, research is always in progress. 